\title{
CrMnFeCoNi high entropy alloys with carbon and nitrogen: mechanical properties, wear and corrosion resistance
}

\author{
L. Chmielak $^{1,2} \cdot$ L. Mujica Roncery ${ }^{3} \cdot$ P. Niederhofer ${ }^{1,2} \cdot$ S. Weber ${ }^{1}$ (D) W. Theisen ${ }^{1}$
}

Received: 16 July 2021 / Accepted: 20 September 2021

Published online: 09 October 2021

(c) The Author(s) $2021 \quad$ OPEN

\begin{abstract}
The use of interstitial elements has been a key factor for the development of different kinds of steels. However, this aspect has been little explored in the field of high entropy alloys (HEAs). In this investigation, the effect of carbon and nitrogen in a near-equiatomic $\mathrm{CrMnFeCoNi} \mathrm{HEA}$ is studied, analyzing their impact on the microstructure, and mechanical properties from $77 \mathrm{~K}$ to $673 \mathrm{~K}$, as well as wear, and corrosion resistance. Carbon and nitrogen are part of the FCC solid solution and contribute to the formation of precipitates. An increase in the yield and ultimate tensile strength accompanied with a decrease in the ductility are the main effects of $C$ and $N$. The impact toughness of the interstitial-free material is higher than that of $\mathrm{C}$ and $\mathrm{C}+\mathrm{N}$ alloyed systems. Compared to $\mathrm{CrNi}$ and $\mathrm{CrMn}$ austenitic steels, the wear resistance of the alloys at room temperature is rather low. The surface corrosion resistance of HEAs is comparable to austenitic steels; nevertheless HEAs are more susceptible to pitting in chloride containing solutions.
\end{abstract}

Keywords High-entropy alloys · Interstitial elements $\cdot$ Mechanical properties $\cdot$ Wear $\cdot$ Corrosion

\section{Introduction}

High-entropy alloys (HEAs) are near equiatomic metallic systems, consisting of FCC, BCC, and HCP structures, as well as a combination of them and other intermetallic phases. They cannot be classified with other alloying systems such as steels, superalloys, Cu-, or Al- based materials, due to the fact that no element can be considered a major component; therefore, they are also known as multi principal element alloys (MPEAs), or complex concentrated alloys (CCAs) [1, 2]. Starting with their development, FCC systems (e.g. CrMnFeCoNi) have attracted the interest because of the particularity of their increased ductility and strength at cryogenic temperatures $[2,3]$, which is an untypical behavior in metallic alloys.
From the metallurgical point of view, it is well known that interstitial elements such as $\mathrm{C}, \mathrm{N}$, and B determine the microstructure and properties of steels. Within steels, one group of FCC alloys that features excellent mechanical properties consists of high-interstitial austenitic stainless steels. These are steels alloyed with $\mathrm{C}+\mathrm{N}$ as interstitial elements in FCC solid solution, showing high strength and ductility due to an increase in the free electron concentration [4], caused by the repulsive interaction between $C$ and $\mathrm{N}$, promoting short-range ordering $[5,6]$.

Few investigations have dealt with the effect of interstitial elements in HEA. Carbon has been added to the CrCoFeMnNi system, promoting the formation of $M_{7} C_{3}$ and $\mathrm{M}_{23} \mathrm{C}_{6}$ carbides, grain refinement, increase in strength, and ductility reduction at room temperature $[7,8]$. In a

S. Weber, weber@wtech.rub.de; L. Mujica Roncery, lais.mujica@uptc.edu.co| ${ }^{1}$ Ruhr-Universität Bochum, Institut für Werkstoffe, 44780 Lehrstuhl Werkstofftechnik, Bochum, Germany. ${ }^{2}$ Present Address: Deutsche Edelstahlwerke Specialty Steel GmbH \& Co. KG, 58452 Witten, Germany. ${ }^{3}$ Grupo de Investigación en Materiales Siderúrgicos e INCITEMA, Universidad Pedagógica y Tecnológica de Colombia, Boyacá, Colombia.

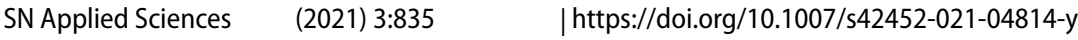


FeNiMnAlCr non-equiatomic system, carbon increases the strength, and the ductility, and affects the work-hardening rate [9]. In CrMnFeCoNi and CrFeCoNi alloys, gas nitrocarburization has been applied in order to build layers below $20 \mu \mathrm{m}$, and this has a direct impact on the hardness of the subsurface and the wear resistance [10]. In this same system, and by means of hot pressing sintering, nitrogen improves the strength of the alloy and reduces its ductility [11]. Concerning corrosion resistance, the carbon addition to the $\mathrm{CrCoFeMnNi}$ system [12] increases the pitting resistance in chlorinated solutions until a addition of $\mathrm{C}$ of 0.5 at $\%$. According to the same investigation, the passive film of the $\mathrm{CrCoFeMnNi}$ system has a porous character (independent if $C$ is added), and pits are formed by the interaction of depleted areas associated with $\mathrm{M}_{23} \mathrm{C}_{6}$ carbides, located near MnS inclusions [12].

The aim of this investigation is to study the role of $C$ and $\mathrm{C}+\mathrm{N}$ as alloying elements in a $\mathrm{CrMnFeCoNi} \mathrm{HEA,} \mathrm{con-}$ sidering their impact on the microstructure, mechanical properties, wear, and corrosion, in order to afford insight into possible additional applications.

\section{Experimental}

Thermo-Calc software with TCNI10 and SSOL4 was used as a reference for the thermodynamic calculations, in order to establish the amount of $\mathrm{C}$ and $\mathrm{N}$ addition as well as the heat treatment temperatures.

Ingots of $5 \mathrm{~kg}$ were produced in a vacuum induction furnace under argon atmosphere at $500 \mathrm{mbar}$, using as raw materials the pure components in their technical degree, in order to more closely approach industry standards. Subsequently, hot forging at $1323 \mathrm{~K}$ of a round bar from an initial diameter of $42 \mathrm{~mm}$ down to $12 \mathrm{~mm}$ was carried out, followed by solution annealing at the same temperature for $30 \mathrm{~min}$ and water quenching.

For the microstructural characterization, metallographic preparation consisting of grinding and polishing down to $1 \mu \mathrm{m}$ was performed, followed by a vibratory polishing. Scanning electron microscopy was conducted in a Leo1530VP equipped with a field emission gun and an EDS detector, which was used to measure the chemical composition of the substitutional elements. For $\mathrm{C}$ and $\mathrm{N}$, a direct fuel cell was employed.

The dimension of the specimens used for the properties characterization tests are shown in Figure 1. Tensile tests were carried out from 77 to $673 \mathrm{~K}$ in a Z100 Zwick universal test machine equipped with a heating/cooling chamber as well as a liquid nitrogen container, under the DIN EN ISO 6892 standard. Vickers hardness testing was performed with 294.3N load (HV30).

\section{SN Applied Sciences}

To analyze the cold-work hardening behavior in the plastic deformation regime, true-stress true-strain curves were fitted to obtain the coefficients of the Ludwik equation [13]:

$\sigma=K \varphi^{n}$

were $\sigma$ is true stress, $\varphi$ true plastic strain, $K$ is the strength factor, and $n$ the strain-hardening exponent.

Charpy impact tests were carried out with a hammer of $300 \mathrm{~J}$ using miniaturized specimens. The measured values were corrected to those of Charpy- $\mathrm{V}$ standard specimens by means of the normalizing factor, based on the work of Kaspar and Faul [14]:

$N F=(B b)^{(3 / 2)}$

$U S E_{S}=\frac{N F_{S}}{N F_{m}} U S E_{m}$

where USE is the upper shelf energy, NF is the normalizing factor (fracture volume under the notch root), $B$ is the width of the specimen, and $b$ is the ligament thickness below the notch [14]. The sub-indexes $S$ and $m$ refer to the standard Charpy- $\mathrm{V}$ specimen and the miniaturized specimen.

Pin abrasion tests were carried out following the ASTM G132-96 standard, using $\mathrm{Al}_{2} \mathrm{O}_{3}(1900-2100 \mathrm{HV})$ and $\mathrm{SiO}_{2}$ (1000-1200 HV) 80/220 mesh abrasive paper, under test conditions $37.2 \mathrm{~N}, 47.8 \mathrm{~min}^{-1}$, and $5.6 \mathrm{~mm} / \mathrm{s}$. Additionally, ball-on-disc wear tests were conducted with a SRV4 - Optimol Instruments $\mathrm{GmbH}$ tribometer, using a $\mathrm{Al}_{2} \mathrm{O}_{3}$ ceramic ball and $10 \mathrm{~N}$ normal force. From this setup, the following quantities were derived:

$f_{a b}=\frac{V_{F}-V_{A}}{V_{F}}$

where $V_{F}$ is the groove volume, $V_{A}$ the pile-up volume, $V_{F}$ $-V_{A}$ the volume loss and $f_{a b}$ the coefficient determining the cutting or ploughing character of the wear groove [15].

Corrosion tests followed the standard DIN 50918, using a Calomel $(\mathrm{Hg} / \mathrm{HgCl})$ reference electrode, a platinum counter electrode, and the alloys as the working electrode. As electrolytes, $3 \mathrm{wt}-\% \mathrm{NaCl}$ and $0.5 \mathrm{M} \mathrm{H}_{2} \mathrm{SO}_{4}$ were used. The equipment consisted of a PGP 201 potentiostat/galvanostat, with a unit equipped with a salt bridge and a Haber-Luggin capillary. 
Table 1 Chemical composition and grain size of the alloys

\begin{tabular}{lllllllll}
\hline Alloy & Fe at-\% & Cr at-\% & Co at-\% & Mn at-\% & Ni at-\% & C at-\% & N at-\% & Grain size $\mu m$ \\
\hline CrMnFeCoNi & 20.33 & 23.11 & 18.70 & 18.83 & 19.03 & - & - & $44 \pm 5$ \\
CrMnFeCoNi-C & 18.60 & 22.69 & 18.83 & 19.67 & 18.98 & 1.24 & - & $11 \pm 1$ \\
CrMnFeCoNi-CN & 13.42 & 20.43 & 25.03 & 19.76 & 20.47 & 0.59 & 0.31 & $33 \pm 3$ \\
\hline
\end{tabular}

Table 2 Stable phases and their composition at $1323 \mathrm{~K}$ according to thermodynamic calculations, Thermo-Calc 2021 TCNI10

\begin{tabular}{lllrlrrrrr}
\hline Alloy & Phase & Amount mol (\%) & Fe (at-\%) & Cr (at-\%) & Co (at-\%) & Mn (at-\%) & Ni (at-\%) & C (at-\%) & N (at-\%) \\
\hline CrMnFeCoNi & Austenite & 100 & 20.33 & 23.11 & 18.70 & 18.83 & 19.03 & - \\
CrMnFeCoNi-C & Austenite & 96.02 & 19.14 & 20.96 & 19.55 & 20.22 & 19.70 & 0.43 & - \\
& $\mathrm{M}_{23} \mathrm{C}_{6}$ & 3.98 & 5.64 & 64.41 & 1.56 & 6.34 & 1.36 & 20.69 & - \\
CrMnFeCoNi-CN & Austenite & 99.00 & 13.54 & 19.99 & 25.28 & 19.94 & 20.66 & 0.44 & 0.15 \\
& $\mathrm{M}_{7} \mathrm{C}_{3}$ & 0.39 & 2.19 & 62.60 & 1.29 & 3.71 & 0.21 & 30.00 & - \\
& $\mathrm{M}_{2}(\mathrm{C}, \mathrm{N})$ & 0.61 & 1.10 & 65.30 & 0.38 & 1.31 & 0.16 & 5.84 & 25.91 \\
\hline
\end{tabular}

\section{Results}

\subsection{Microstructure}

The microstructure of the alloys consisted of an FCC matrix, with an homogeneously distributed and well developed austenitic structure consisting of recrystallized grains (see Fig. 2 and Table 1). The alloy CrMnFeCoNi is fully austenitic (Fig. 2 a), whereas the alloys $\mathrm{CrMnFeCoNi-C}$ and $\mathrm{CrMnFeCoNi-CN}$ consists of an austenitic matrix with precipitates (Fig. 2 b and c, respectively). The alloy with larger grain size was the interstitial-free CrMnFeCoNi alloy ( $44 \mu$ $\mathrm{m})$. The $\mathrm{CrMnFeCoNi-C}$ alloy exhibits a finer grain size (11 $\mu \mathrm{m})$. The $\mathrm{C}+\mathrm{N}$ HEA exhibits an intermediate grain size of $33 \mu \mathrm{m}$. In the case of the reference material $\mathrm{CrMnFeCoNi}$, few inclusions were found from impurities and oxidation processes, with a total content of $0.35 \mathrm{vol} .-\%$.

For the $\mathrm{CrMnFeCoNi-C}$, carbides were present (3.4 vol-\% according to the SEM micrographs, Fig. 2) on the grain boundaries as well as inside the grains. According to the equilibrium calculations (see Table 2), $\mathrm{M}_{23} \mathrm{C}_{6}$ carbides were expected. EDS point measurements on coarse carbides indicated $50.21 \mathrm{Cr}$ and $28.6 \% \mathrm{C}$ (atomic). Due to the nature of the EDS technique, carbon measurements should be interpreted from a qualitative point of view.

For the $\mathrm{CrMnFeCoNi-CN}$ alloy, precipitates ( $0.8 \mathrm{vol}-\%)$ were present, as indicated in Fig. $2 \mathrm{c}$ and $\mathrm{d}$. In the EDSmap it can be observed that the precipitates are rich in chromium and carbon, whereas the elements cobalt, iron, nickel and manganese remain in the austenitic matrix. In case of nitrogen, no preferential partition can be observed. The precipitates are located preferentially at the grain boundaries. Nevertheless, due to the small phase fraction and size of the precipitates, it was not possible to determine by XRD the type of carbides or carbonitrides. The EDS-map also indicates segregation of the substitutional elements. Especially, one can identify $\mathrm{Mn}-\mathrm{Ni}$ rich areas coincident with $\mathrm{Co}-\mathrm{Fe}$ meager regions.

Taking into account that the tree alloys underwent the same process route, the volume fraction of the precipitates (Tables 1 and 2) is considered the main factor affecting the grain size distribution.

\subsection{Mechanical properties}

From the tensile tests, the yield strength, ultimate tensile strength, uniform elongation, and total elongation were extracted, as well as the true stress - true strain curves (see Figs. 3 and 4).

In general, the results of the tensile tests showed that as the temperature decreased, the alloys experienced an increase in both the ductility (uniform and total elongation) and strength (yield and ultimate strength), as seen in Figs. 3 and 4. An exception was the case of the tests at $673 \mathrm{~K}$ in the $\mathrm{C}$ and $\mathrm{C}+\mathrm{N}$ alloyed systems, which exhibited higher ductility than at $473 \mathrm{~K}$. An additional feature observed in the CrMnFeCoNi alloy at 673 is the Portevin Le Chatelier effect, indicated by the serrated plastic flow.

The addition of interstitial elements increased the yield strength and the ultimate tensile strength as indicated in Fig. $4 \mathrm{a}$ and b). In this case, various effects contributed to this behavior, namely: solid solution strengthening (carbon and nitrogen in the interstitial FCC sublattice), precipitation hardening (Zener pinning and Orowan strengthening), and a finer grain size (Hall-Petch effect).

In most of the cases, the ductility of the alloys containing $\mathrm{C}$ or $\mathrm{C}+\mathrm{N}$ was lower than that of their interstitial-free counterpart. The exception to this effect was observed in the $\mathrm{CrMnFeCoNi}-\mathrm{CN}$ alloy at 473 and $673 \mathrm{~K}$. In case of the 
Fig. 1 Schematic representation of the specimens used in this investigation. a Tensile test, b Impact test, c Ball and disc wear test, $\mathbf{d}$ Pin abrasion test a)

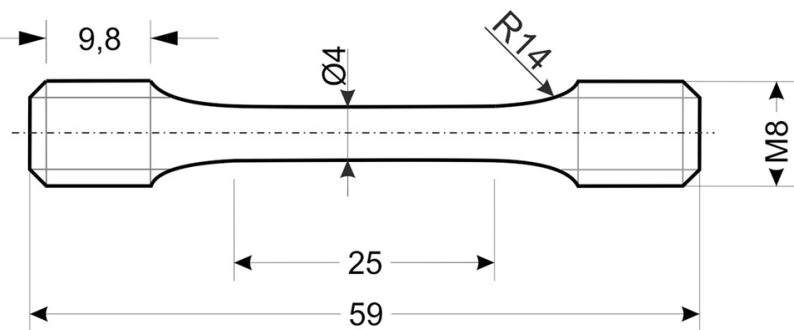

b)

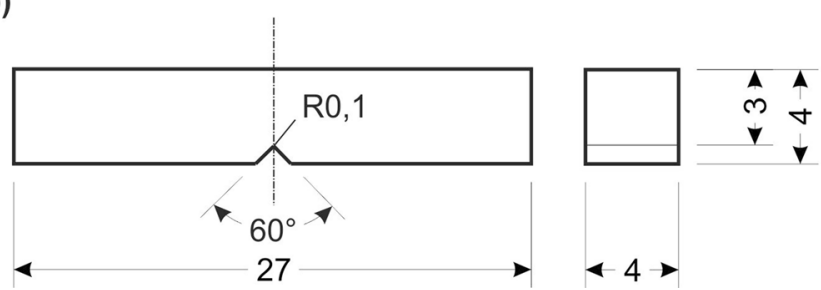

c)

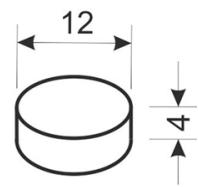

d)

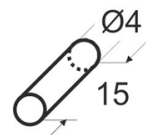

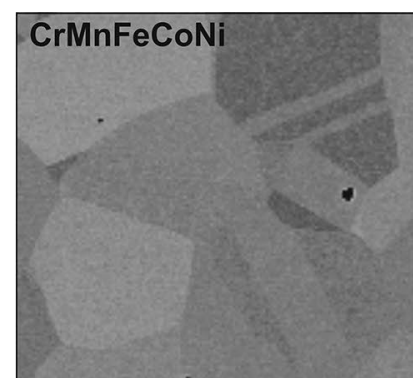

a)
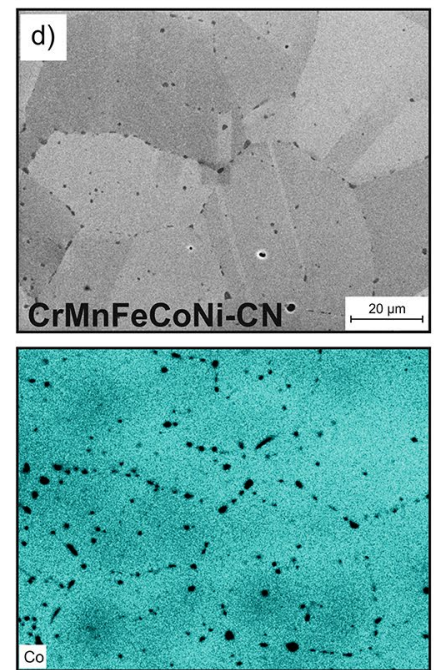

$20 \mu \mathrm{m}$
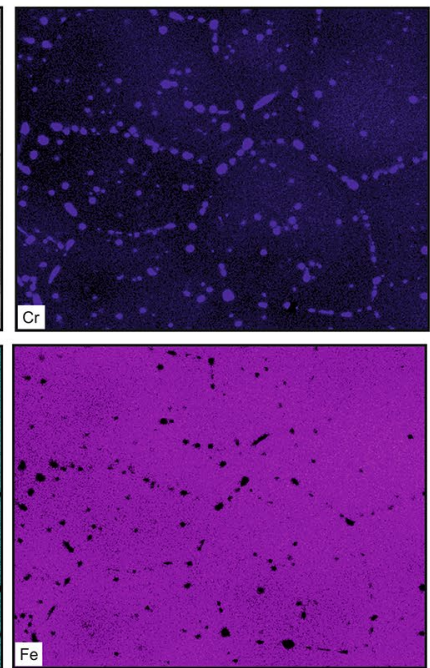

CrMnFeCoNi-CN

c)
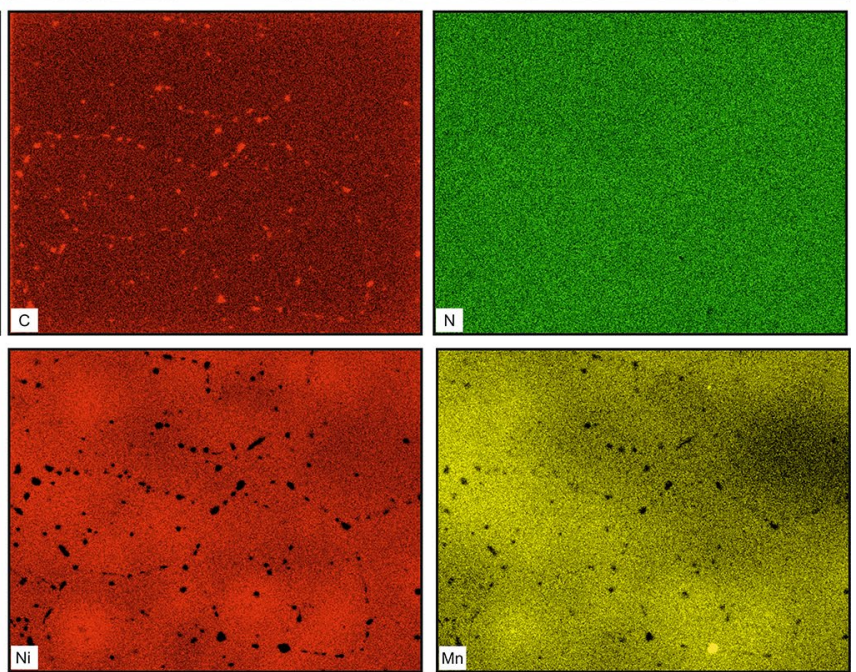

Fig. 2 SEM micrographs of the high-entropy alloys produced: a CrMnFeCoNi, b CrMnFeCoNi-C, c CrMnFeCoNi-CN. d EDS map of the CrMnFeCoNi-CN alloy

$\mathrm{C}+\mathrm{N}$ alloyed system, at higher temperatures the uniform and the total elongation were higher than the corresponding values of the other alloys (Figs. 3, and $4 \mathrm{c}$ and d).
In all systems and temperatures, an intense cold-work hardening behavior is observed, as indicated in the true stress - true strain curves in Fig. 3. The coefficients of the Ludwik equation (Eq. 1) obtained from these curves are 

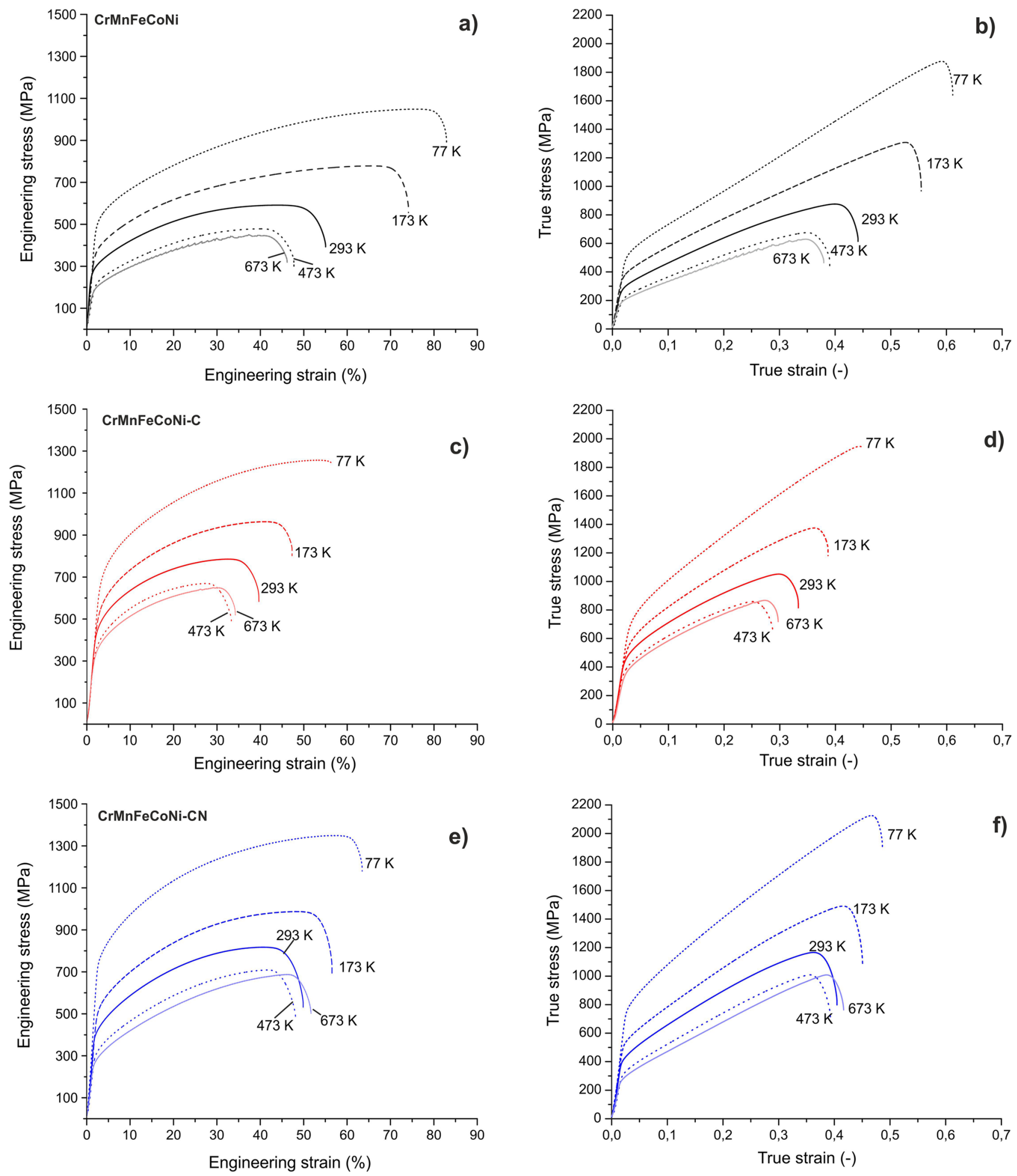

Fig. 3 Engineering and true stress-strain curves of the high-entropy alloys

listed in Table 3. The HEAs studied in this investigation show high values of the strain-hardening exponent, indicating an intense cold-work hardening behavior. The addition of $\mathrm{C}$ or $\mathrm{C}+\mathrm{N}$ decreases the value of the $n$ exponent, but increases the $K$ proportionality constant. On the one hand, $\mathrm{C}$ and $\mathrm{N}$ in the fcc solution or as precipitates increases the strength of the alloy. On the other hand, the addition of $\mathrm{C}$ and $\mathrm{N}$ in these alloys modify the deformation 
- CrMnFeCoNi

$\rightarrow$ CrMnFeCoNi-C

$\triangle-$ CrMnFeCoNi-CN
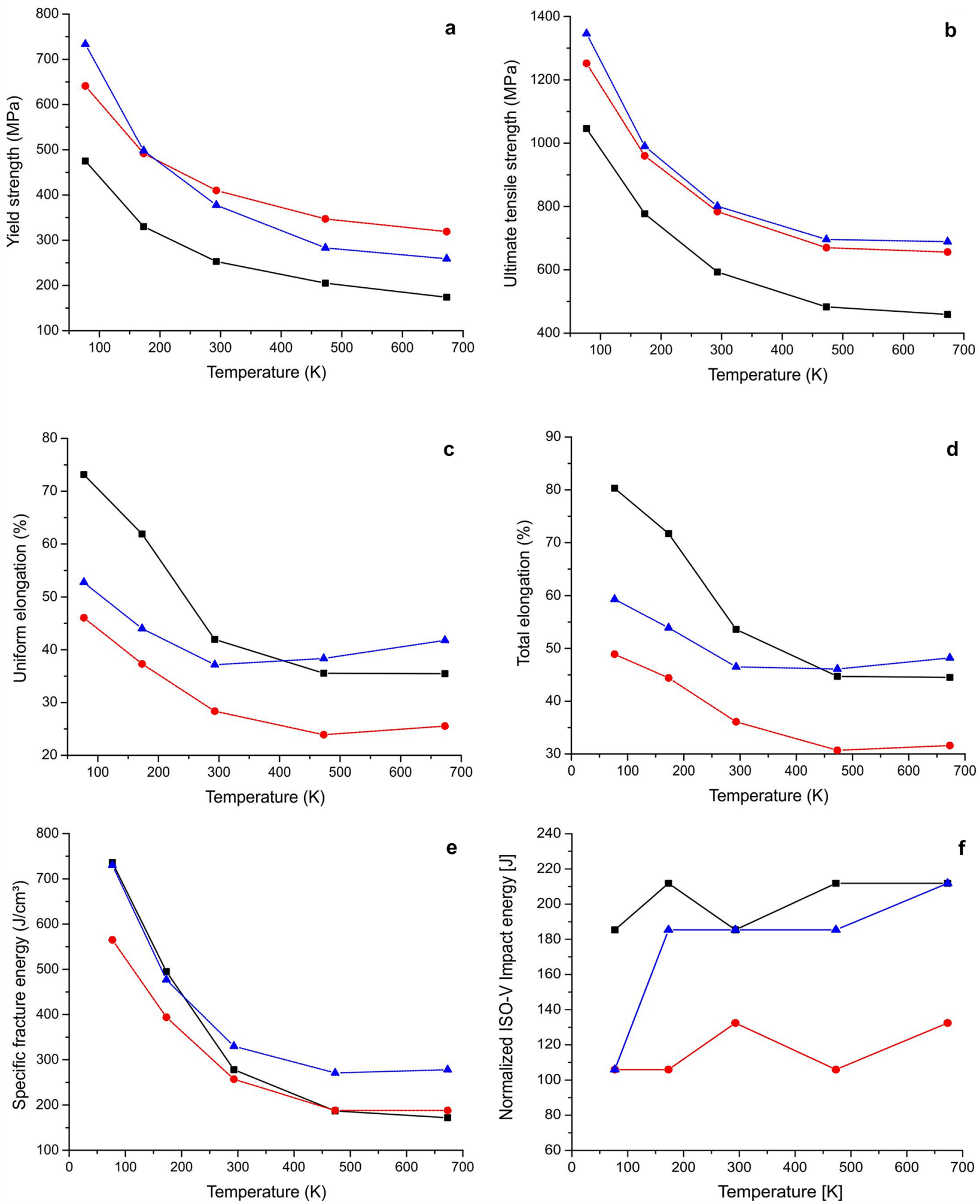

Fig. 4 Comparison of the strength and ductility of the high-entropy alloys: a yield strength, $\mathbf{b}$ ultimate tensile engineering strength, $\mathbf{c}$ uniform elongation, $\mathbf{d}$ total elongation, e specific fracture energy, $\mathbf{f}$ normalized ISO-V impact energy of the alloys 
Table 3 Ludwik coefficients of the HEA in the plasticdeformation regime, according to Equation 1

\begin{tabular}{llccccc}
\hline Alloy & $\mathrm{T}$ & 77 & 173 & 293 & 473 & 673 \\
\hline CrMnFeCoNi & $K$ & 2396.6 & 1717.2 & 1298.7 & 1195.6 & 1159.9 \\
& $n$ & 0.962 & 0.829 & 0.669 & 0.740 & 0.776 \\
CrMnFeCoNi-C & $K$ & 2676.6 & 1974.8 & 1538.5 & 1383.8 & 1413.4 \\
& $n$ & 0.774 & 0.631 & 0.495 & 0.468 & 0.540 \\
CrMnFeCoNi-CN & $K$ & 2795.7 & 2160.1 & 1847.5 & 1840.9 & 1861.5 \\
& $n$ & 0.761 & 0.725 & 0.697 & 0.812 & 0.881 \\
\hline
\end{tabular}

Table 4 Wear resistance $\mathrm{W}^{-1} \times 10^{4}$ pin-on-paper against $\mathrm{SiO} 2$ (900$1200 \mathrm{HV} 0,05)$ and $\mathrm{Al}_{2} \mathrm{O}_{3}(1800-2250 \mathrm{HV} 0,05)$ size $80^{*}$ and $220^{* *}$ mesh

\begin{tabular}{llllll}
\hline Alloy & $\mathrm{SiO}_{2}{ }^{*}$ & $\mathrm{SiO}_{2}{ }^{* *}$ & $\mathrm{Al}_{2} \mathrm{O}_{3}{ }^{*}$ & $\mathrm{Al}_{2} \mathrm{O}_{3}{ }^{* *}$ & $\mathrm{HV} 30$ \\
\hline CrMnFeCoNi & 1.93 & 2.54 & 1.75 & 1.90 & $130 \pm 1$ \\
CrMnFeCoNi-C & 1.94 & 2.62 & 1.79 & 1.93 & $200 \pm 1$ \\
CrMnFeCoNi-CN & 2.18 & 2.79 & 1.91 & 2.06 & $189 \pm 2$ \\
\hline
\end{tabular}

Table 5 Average friction coefficient $\mu_{s}$ groove depth, groove volume $\left(V_{F}\right)$, pile-up volume $\left(V_{A}\right), f_{a b}$ coefficient

\begin{tabular}{llllll}
\hline Alloy & $\mu_{s}$ & $\begin{array}{l}\text { wear depth } \\
\mu \mathrm{m}\end{array}$ & $\begin{array}{l}\mathrm{V}_{F} \\
10^{6} \mu \mathrm{m}^{3}\end{array}$ & $\begin{array}{l}\mathrm{V}_{A} \\
10^{6} \mu \mathrm{m}^{3}\end{array}$ & $\mathrm{f}_{a b}$ \\
\hline CrMnFeCoNi & 1.48 & 48 & 100.9 & 9.6 & 0.905 \\
CrMnFeCoNi-C & 1.46 & 45 & 84.5 & 6.0 & 0.929 \\
CrMnFeCoNi-CN & 1.46 & 45 & 97.2 & 8.1 & 0.928 \\
\hline
\end{tabular}

mechanisms in such a way that the plastic deformation is slightly constrained.

The specific fracture energy was obtained from the integral of the engineering stress-strain curve (Fig. 4 e). This property is associated with the capacity of energy absorption during deformation and toughness of the material, which decreased as the temperature increased. At low temperatures, $\mathrm{CrMnFeCoNi}$ and $\mathrm{CrMnFeCoNi-CN}$ showed similar values. At higher temperatures, the alloy with $\mathrm{C}+\mathrm{N}$ exhibited higher fracture energy. In all cases the carbon-alloyed system exhibited the lowest values. In spite of the greater strength of the CrCoFeMnNi-CN alloy, the material that was able to absorb more energy was the interstitial-free material $\mathrm{CrMnFeCoNi}$, probably due to its greater ductility.

Another property associated with the toughness is the Charpy impact energy (Fig. 4 f). Due to the fact that miniaturized specimens were used, the normalized values corresponding to standard specimens were obtained by Eqs. 2 and 3. The interstitial-free HEA exhibits the highest impact energy, followed by the $\mathrm{C}+\mathrm{N}$ alloy and the $\mathrm{C}$ variant. The loss of ductility associated with $\mathrm{C}$ and $\mathrm{C}+\mathrm{N}$ may be the main factor affecting the impact energy. The
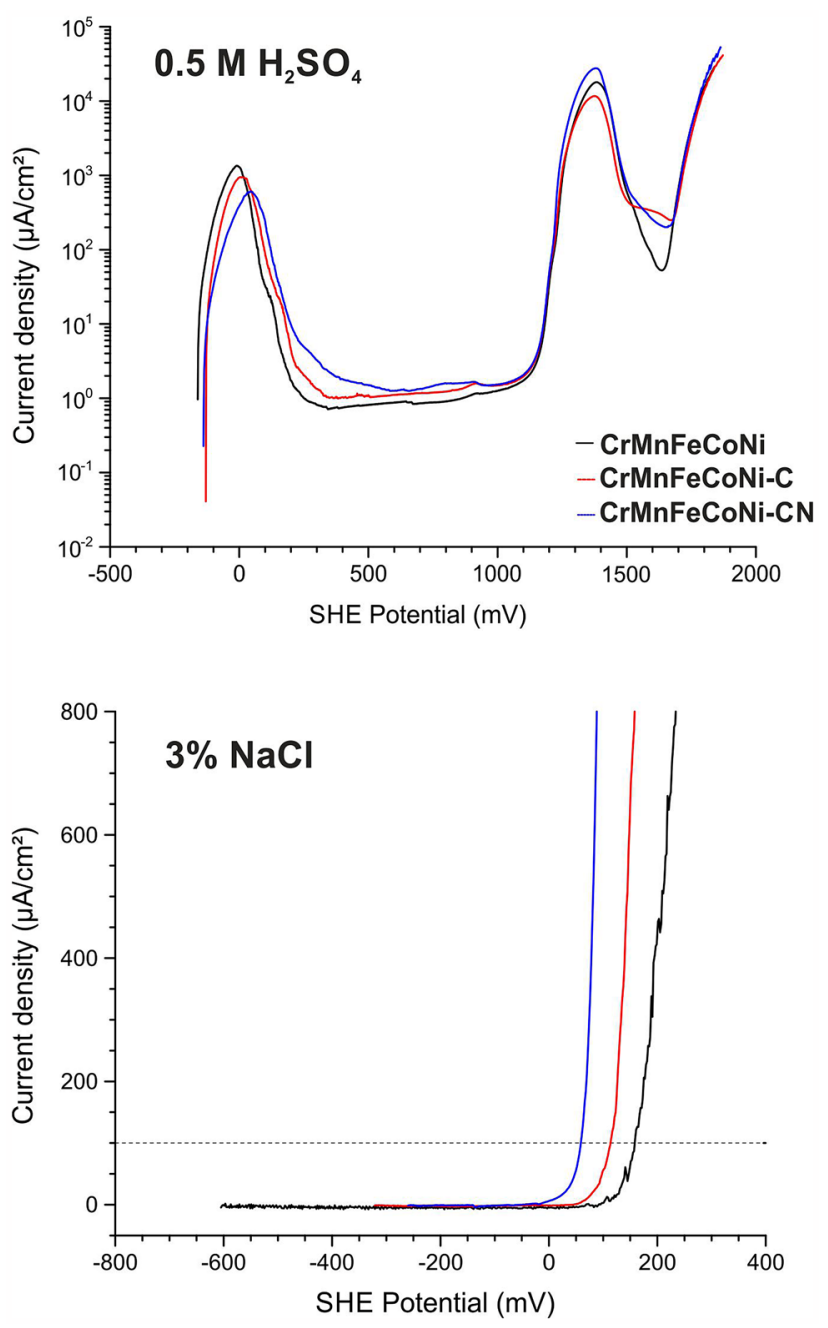

Fig. 5 Current density - potential curves. a) $0.5 \mathrm{M} \mathrm{H}_{2} \mathrm{SO}_{4}$ solution. b) and c) 3 wt. $\% \mathrm{NaCl}$ solution

normalized values obtained in this study for the $\mathrm{CrMn}$ FeCoNi system exhibit no temperature dependence, with values around $180 \mathrm{~J}-220 \mathrm{~J}$, which are in agreement with values reported in the literature [16]. There is, however, a negative effect caused by $C$. Carbon lowers the average absorbed energy ( $\approx 100 \mathrm{~J}-130 \mathrm{~J})$. Carbon and nitrogen HEA exhibit an upper shelf energy around $180 \mathrm{~J}-200 \mathrm{~J}$ 
Table 6 Electrochemical corrosion test results in $\mathrm{H}_{2} \mathrm{SO}_{4} 0.5 \mathrm{M} . E_{\text {corr }}$ : Corrosion potential. $E_{p p}$ : primary passivation potential. $E_{p}$ : potential at the begging of the stable passive region. $E_{B}$ : breakdown poten- tial. $i_{c r i t}:$ critical corrosion density at $E_{p p} . i_{p}:$ minimum corrosion density at the passive area

\begin{tabular}{|c|c|c|c|c|c|c|}
\hline \multirow[t]{2}{*}{ Alloy } & \multicolumn{4}{|c|}{$\mathrm{mV} / \mathrm{SHE}$} & \multicolumn{2}{|c|}{$\mu \mathrm{A} / \mathrm{cm}^{2}$} \\
\hline & $E_{\text {corr }}$ & $E_{P P}$ & $E_{P}$ & $E_{B}$ & $i_{\text {crit }}$ & $i_{P}$ \\
\hline CrMnFeCoNi & -162 & -9 & 344 & 1638 & 1348 & 0.7 \\
\hline CrMnFeCoNi-C & -138 & 11 & 345 & 1664 & 944 & 1.0 \\
\hline $\mathrm{CrMnFeCoNi-CN}$ & -138 & 46 & 404 & 1656 & 602 & 1.2 \\
\hline
\end{tabular}

Table 7 Electrochemical corrosion test results in $3 \% \mathrm{NaCl}$ solution. $E_{\text {corr }}$ : corrosion potential. $E_{B}$ : breakdown potential at $100 \mu \mathrm{A} / \mathrm{cm}^{2}$

\begin{tabular}{lll}
\hline Alloy & $\begin{array}{l}E_{\text {corr }} \\
\text { mV/SHE }\end{array}$ & $\begin{array}{l}E_{B} \\
\mathrm{mV} / \mathrm{SHE}\end{array}$ \\
\hline CrMnFeCoNi & 97 & 162 \\
CrMnFeCoNi-C & 45 & 114 \\
CrMnFeCoNi-CN & -50 & 52 \\
\hline
\end{tabular}

and a sudden drop in the absorbed energy to $100 \mathrm{~J}$ at $77 \mathrm{~K}$. The cause of these effects is not yet clear, since the fracture surfaces observed are ductile in all cases.

Although the specific fracture energy and the Charpy impact energy both related with the toughness of the material, their tendencies are very different (see Fig. $4 \mathrm{e}$ and $\mathrm{f}$ ), where the key factor is the deformation rate. For slow rate deformation during tensile tests, the behavior is strongly affected by the temperature. For high deformation rates during impact test, the temperature dependance is not so strong.

\subsection{Wear resistance}

The wear resistance measured by pin-on-paper tests against different abrasives $\left(\mathrm{SiO}_{2}\right.$ and $\left.\mathrm{Al}_{2} \mathrm{O}_{3}\right)$ in two different grit sizes is shown in Table 4. It can be seen that the wear resistance decreases with increasing grit size and hardness of the abrasive counterbody. Furthermore, the wear resistance of $\mathrm{CrMnFeCoNi-CN}$ is higher than that of $\mathrm{CrMnFeCoNi-C}$, while $\mathrm{CrMnFeCoNi}$ exhibited the lowest values. As a reference, 304 stainless steel, Hadfield steel, and $18 \mathrm{Mn} 18 \mathrm{CrCN} 96$ austenitic steels exhibit wear resistance values against 80 flint paper of $2.56 \times 10^{4}, 3.24 \times 10^{4}$, and $2.82 \times 10^{4}$, respectively [4]. Compared to the austenitic steels, the high-entropy alloys investigated in this study exhibited lower wear resistance in this test setup.

Wear-testing results using the ball-on-disc configuration are summarized in Table 5 . It is clear that the average friction coefficient does not differ significantly between the three investigated alloys. However, the groove volume and the corresponding pile-up formed during testing showed differences. In this test setup, $\mathrm{CrMnFeCoNi-C}$ exhibited the highest wear resistance, which was expressed by lower volumes of grooves formed by abrasive action of the $\mathrm{Al}_{2} \mathrm{O}_{3}$-ball during sliding. $\mathrm{CrMnFeCoNi-CN}$ was characterized by slightly lower wear resistance, while the interstitial-free $\mathrm{CrMnFeCoNi}$ exhibited the lowest values in this comparison as well. Considering the $f_{a b}$ coefficient, values close to 1 denote a microcutting character, whereas 0 indicates microploughing (plastic deformation) [15]. In this wear system, cutting is the predominant wear mechanism.

\subsection{Corrosion resistance}

Electrochemical corrosion test results in sulfuric acid are shown in Fig. 5 and Table 6. During testing in $\mathrm{H}_{2} \mathrm{SO}_{4}$, following an active peak, the formation of a passive layer occurred, which was expressed by the decrease of the current density until it reached a plateau, followed by a transpassive region and finally the breakdown potential. Regarding the critical current, corresponding to the primary passivation potential, $\mathrm{C}$ and $\mathrm{N}$ seem to have a favorable effect, slightly lowering this value. The value of the current density in the passive areas, as well as the extension, can be seen as most important parameters that characterize resistance against general surface corrosion. It is clear from Fig. 5 that the extent of the passive region is similar in all the investigated alloys. The differences in the passive current density are rather small as well. CrCoFeMnNi exhibited the lowest passive current, followed by $\mathrm{CrMnFeCoNi-C}$ and $\mathrm{CrMnFeCoNi-CN}$.

In sodium chloride solution (Fig. 5 and Table 7), the breakdown potential can be regarded as a decisive value. A higher breakdown potential of the passive layer means improved resistance against localized pitting corrosion. In this case, it seems that the addition of $\mathrm{C}$ and $\mathrm{N}$ elements reduced the breakdown potential (Fig. 5 and Table 7). The addition of $\mathrm{C}$ and $\mathrm{N}$ shifts the corrosion potential to less noble values. The formation of chromium and carbon rich precipitates may have a 
detrimental effect on the corrosion resistance of the HEA in chloride containing solutions.

\section{Discussion}

\subsection{Effect of $\mathrm{C}$ and $\mathrm{N}$ on the mechanical properties}

For the HEAs in this investigation, the general tendency of an increase in the strength and ductility as the temperature decreases (Figs. 3 and 4), agrees with previous investigations on $\mathrm{CrMnFeCoNi}$ systems. Otto et al. found a higher work hardening as the temperature decreases, where the governing deformation mechanisms are $\{111\}$ planar slip, dislocation cell structures, stacking faults and twinning [17]. These mechanisms activate gradually at different amounts of deformation and stress, where twinning is shown at low temperatures, promoting the dynamic Hall-Petch effect $[3,17]$.

The addition of carbon to HEAs increased the strength of the alloys (see Table 3). This agrees with findings of Wu et al. [18], who studied CrMnFeCoNi with 0.5 at.-\% C, highlighting a more pronounced twinning activity than that of the C-free material, including the formation of nanotwins nucleated at the grain boundaries. A similar tendency has also been observed also with a 1.1 at- $\%$ C alloy [9].

Concerning the effects of $\mathrm{C}+\mathrm{N}$ on high-entropy alloys in this investigation, clearly the solid solution strengthening effect of these atoms on the interstitial fcc lattice is reflected in the increase of the yield strength (Fig. 4a). An additional effect of the addition of $\mathrm{C}$ and $\mathrm{N}$ in the current investigation is the formation of precipitates, which are responsible for the dislocation pinning and grain refinement, favoring the strength of the materials.

The cold work hardening behavior in dependance with the temperature can be analyzed through the $K$ and $n$ coefficients of the Ludwik equation (Eq. 1, Table 3) . Independent whether it is interstitial free or not, $K$ always decreases as the temperature increases, denoting a softening behavior. The $n$ exponent shows a maximum at 77K, it decreases at temperatures close to room temperature, and increases again at $673 \mathrm{~K}$. This behavior indicates two different major deformation mechanisms, one operating at subzero conditions and other at the temperatures above $473 \mathrm{~K}$. In the last case, as temperature increases, the mobility and diffusion of interstitial and substitutional atoms is larger, therefore it can be expected a stronger interaction between atoms and dislocations. Nevertheless, the deformation mechanisms are not in the scope of the present investigation and should be further studied.

There is, though, for the CrMnFeCoNi system a negative effect of $\mathrm{C}$ and $\mathrm{C}+\mathrm{N}$ on the ductility and cold-work hardening behavior. A recent investigation of the equiatomic $\mathrm{CrMnFeCoNi}$ system alloyed with $\mathrm{C}$ and $\mathrm{N}$ separately (not combined) performed by Astafurova et al. suggests that carbon is the element responsible for the embrittlement of this particular system, whereas nitrogen enhances both strength and ductility [19], due to an inhomogeneous distribution of $\mathrm{C}$ in the microstructure arising from the solidification dendritic structures and segregation. The beneficial effect of $\mathrm{N}$ on the systems $\mathrm{CoCrFeMnNi}$ and CrFeMnNi has been also documented by Xiong et at. [20] and Traversier et al. [21], respectively, which the authors associate with, solid-solution strengthening, precipitation strengthening, and grain refinement [20].

Additional effects of the combination of $\mathrm{C}$ and $\mathrm{N}$ as interstitial elements during plastic deformation is the pinning of dislocations by these atoms, associated with the binding enthalpy of dislocations and interstitials, as well as short-range ordering and higher concentration of free electrons, which have been documented for high interstitial austenitic steels of the system Fe-Cr-Mn-C-N [4-6, $23,24]$. Further studies on this topic will be necessary to establish if the $\mathrm{CrMnFeCoNi}$ also benefits from the effects reported by Gavriljuk et al., nevertheless the $\mathrm{C}$ and $\mathrm{N}$ contents should be reduced and the heat treatment temperatures adjusted in order to ensure a fully fcc single phase structure.

The structure of the $\mathrm{CrMnFeCoNi}$ interstitial-free equiatomic system is stable, and no $\alpha^{\prime}$ - or $\varepsilon$-martensitic transformation has be documented in the literature, but twinning $[3,17]$. As this system is already stable, $\mathrm{C}$ and $\mathrm{N}$ may change the stacking fault energy, affecting slightly the deformation mechanisms, for example the critical resolved shear stress for twinning, twin thickness, among others. For metastable austenites of the system $\mathrm{Fe}_{48.5} \mathrm{Mn}_{30}$ $\mathrm{Co}_{10} \mathrm{Cr}_{10} \mathrm{C}_{0.5} \mathrm{~N}_{1.0}$ [22], the combined addition of $\mathrm{C}$ and $\mathrm{N}$ reduces the formation of $\varepsilon$-martensite, increases strength but reduces ductility.

For the CrMnFeCoNi HEAs, it seems that the combined addition of $\mathrm{C}$ and $\mathrm{N}$ does not exhibit the synergistic effect observed in the $\mathrm{C}+\mathrm{N} \mathrm{Fe}-\mathrm{Cr}-\mathrm{Mn}$ steels [4-6]. In case of the HEA in this investigation, the negative effects of carbon on the ductility are more predominant than the beneficial effects of $\mathrm{N}$.

\subsection{Impact of $\mathrm{C}$ and $\mathrm{N}$ on wear and corrosion resistance}

Resistance against abrasive wear can be influenced by different material characteristics, which include microstructural features as well as mechanical properties, in particular hardness. In the case of single phase metallic alloys or those containing relatively small hard phases, which are attacked by comparatively coarse and hard particles, 
small differences in hardness should not have a significant influence [25]. As already described, $\mathrm{CrMnFeCoNi-C}$ and $\mathrm{CrMnFeCoNi}-\mathrm{CN}$ due to addition of interstitials exhibit slightly increased hardness compared with $\mathrm{CrMnFeCoNi}$, while, however, showing only small differences in resistance during pin-on-paper test (Tables 4 and 5). In contrast, the slightly higher resistance of high interstitial austenitic stainless steels to abrasive wear could be a result of the higher hardness (approximately $30 \%$ ), improved toughness, and cold-work hardening ability [4].

As shown in Table 5, CrMnFeCoNi-C and CrMnFeCoNi$\mathrm{CN}$ by trend exhibit slightly decreased wear track depth compared to interstitial-free and softer $\mathrm{CrMnFeCoNi}$ when tested in ball-on-disc configuration. However, high resistance to abrasive wear would require larger amounts of hard phases.

According to the results of the wear setups shown in Sect. 3.3, high-entropy alloys exhibit rather low abrasive wear resistance at room temperature compared with other austenitic materials, which is a limitation on their application. However, the slight increase in wear resistance due to the addition of interstitial elements agrees with the findings of Xiao et al [26]. They found a beneficial effect of increased carbon content on the wear resistance of $\mathrm{CrMnFeCoNi} \mathrm{HEA} \mathrm{which} \mathrm{they} \mathrm{attributed} \mathrm{to} \mathrm{the} \mathrm{precipita-}$ tion of $\mathrm{M}_{7} \mathrm{C}_{3}$ carbides, which in turn was accompanied by an increase in hardness. Nevertheless, taking into account that the mechanical properties of HEAs are significantly improved at cryogenic temperatures, the wear resistance at subzero conditions could improve as well.

Previous investigations with high-interstitial austenitic steels have shown a correlation between the ultimate strength and the specific energy absorption with the cavitation resistance [29], where the incubation time increases and the maximum erosion rate decreases with improving mechanical properties. Translating this concept to HEAs, FCC CrMnFeCoNi is promising material where a high mechanical response at low temperatures is required, in the space technology among others, and for applications for storage and transportation of compressed or liquefied gases at subzero temperatures, such as $\mathrm{He}, \mathrm{N}_{2}, \mathrm{CH}_{4}, \mathrm{CO}_{2}$ etc. Low-temperature wear experiments [30] or cavitation tests could be additional areas of research, taking into consideration that under cryogenic conditions, rotating parts do not use lubricants, and that the systems transporting liquefied gases are susceptible to cavitation associated with pressure changes.

As a comparison, in the case of high-interstitial austenitic stainless steels, the addition of both nitrogen and carbon may have a positive impact on resistance against pitting corrosion, while the influence on surface corrosion is rather low [4, 31]. Compared to that group of steels, highentropy alloys exhibit slightly lower performance against pitting corrosion in chloride-containing solutions, whereas the surface corrosion behavior is similar. The presence of the precipitates can be responsible for the lower pitting resistance of the $\mathrm{CrMnFeCoNi}$ studied in this investigation.

In terms of resistance to corrosion, the alloying content is a key factor. Especially a high amount of chromium, dissolved in the metallic matrix, is beneficial against virtually any type of corrosive attack, since it allows for the formation of a thin but dense passive layer. In the case of localized corrosion induced by chloride ions, for austenitic stainless steels it has been shown, that nitrogen improves corrosion resistance by increasing breakdown potential. This effect is even more pronounced if both nitrogen and molybdenum are present as alloying elements [27]. However, the elements can only contribute to corrosion resistance if they are dissolved in the matrix. Any kind of chromium-rich precipitate can act as defect of the passive layer and thus contribute to deterioration of pitting corrosion resistance [28]. This could be a reason for both lower breakdown potential of HEA investigated in this study compared with high interstitial austenitic stainless steels and decreased resistance of $\mathrm{CrMnFeCoNi-C}$ and $\mathrm{CrMn}$ FeCoNi-CN compared to CrMnFeCoNi. This is confirmed by the findings of Lu et al. [32] and Menghani et al. [33].

Resistance to general surface corrosion as investigated by potentiodynamic polarization measurements in sulfuric acid is mainly depending on the chromium content dissolved in the martensitic matrix. An increased amount of $\mathrm{Cr}$ decreases both passivation as well as passive current density yet characterizing lower corrosion rates [34]. Since chromium content of the HEA investigated in this study is comparable to that of high interstitial austenitic stainless steels, the surface corrosion behavior is similar as well. General surface corrosion behavior is less susceptible to precipitates as compared to localized corrosion.

The passive layer of HEA seems to be not as stable as that of high interstitial austenitic stainless steels, and thus more susceptible to pitting corrosion in chloridecontaining solutions, which could limit the application of HEA in marine environments. Susceptibility to localized corrosion is even increased by the presence of a second phase, as stated by Lu et al. [32] and confirmed by Menghani et al. [33], which was attributed to the impact of the second phase, e.g. carbides, on the formation of passive films. This is consistent with the findings in the present study. Aluminum-alloyed HEA variants could have more promising applications in this field, as indicated in recent investigations $[33,35]$. However, the addition of Al could strongly affect the stability of the FCC structure towards a BCC structure, depending on its content. 


\section{Summary and conclusions}

The effect of $\mathrm{C}$ and $\mathrm{C}+\mathrm{N}$ on near-equiatomic $\mathrm{CrMnFeCoNi}$ high-entropy alloys was examined. The following conclusions can be drawn:

- As the temperature increases from $77 \mathrm{~K}$ to $673 \mathrm{~K}$, the alloys experience a decrease in ductility, strength and specific fracture energy.

- The addition of interstitial elements increases the yield strength and ultimate tensile strength, while decreasing the ductility.

- The impact toughness of HEA between $77 \mathrm{~K}$ an 673 $\mathrm{K}$ is rather constant, where $\mathrm{C}$ and $\mathrm{N}$ have a tendency to decrease this property, the effect of carbon being marked.

- The wear resistance at room temperature of HEA shown by the pin-on-paper tests is lower than that of austenitic steels. Using the ball-on-disc configuration, interstitial-free $\mathrm{CrMnFeCoNi}$ exhibited the lowest values, with cutting being the predominant wear mechanism.

- HEAs exhibit performance against surface and pitting corrosion similar to that of austenitic steels.

Funding Open Access funding enabled and organized by Projekt DEAL.

Data availability The raw/processed data required to reproduce these findings cannot be shared at this time as the data also forms part of an ongoing study.

\section{Declarations}

Conflict of interest The authors declare that they have no conflict of interest.

Open Access This article is licensed under a Creative Commons Attribution 4.0 International License, which permits use, sharing, adaptation, distribution and reproduction in any medium or format, as long as you give appropriate credit to the original author(s) and the source, provide a link to the Creative Commons licence, and indicate if changes were made. The images or other third party material in this article are included in the article's Creative Commons licence, unless indicated otherwise in a credit line to the material. If material is not included in the article's Creative Commons licence and your intended use is not permitted by statutory regulation or exceeds the permitted use, you will need to obtain permission directly from the copyright holder. To view a copy of this licence, visit http://creativecommons. org/licenses/by/4.0/.

\section{References}

1. Miracle DB, Senkov ON (2017) A critical review of high entropy alloys and related concepts. Acta Materialia 122:448-511

2. George EP, Curtin WA, Tasan CC (2020) High entropy alloys: a focused review of mechanical properties and deformation mechanisms. Acta Materialia 188:435-474
3. Laplanche G, Kostka A, Horst OM, Eggeler G, George EP (2016) Microstructure evolution and critical stress for twinning in the CrMnFeCoNi high-entropy alloy. Acta Materialia 118:152-163

4. Gavriljuk VG, Berns H, Riedner S (2013) High interstitial stainless austenitic steels. Springer-Verlag, Berlin-Heidelberg

5. Berns H, Gavriljuk VG, Riedner S, Tyshchenko A (2007) High strength stainless austenitic $\mathrm{CrMnCN}$ steels - part I: alloy design and properties. Steel Res Int 78(9):714-719

6. Shanina BD, Gavriljuk VG, Berns H (2007) High strength stainless austenitic CrMnCN steels - p III: electronic properties. Steel Res Int 78(9):724-728

7. Ko JY, Hong SI (2018) Microstructural evolution and mechanical performance of carbon-containing CoCrFeMnNi-C high entropy alloys. J Alloys Compd 743:115-125

8. Li Z (2019) Interstitial equiatomic CoCrFeMnNi high-entropy alloys: carbon content, microstructure, and compositional homogeneity effects on deformation behavior. Acta Materialia 164:400-412

9. Wang Z, Baker I (2016) Interstitial strengthening of a f.c.c. FeNiMnAICr high entropy alloy. Mater Lett 180:153-156

10. Lindner T, Löbel M, Saborowski E, Rymer L-M, Lampke T (2020) Wear and corrosion behaviour of supersaturated surface layers in the high-entropy alloy systems $\mathrm{CrMnFeCoNi}$ and $\mathrm{CrFeCoNi}$. Crystals 10:110

11. Xie Y, Cheng H, Tang Q, Chen W, Chen W, Dai P (2018) Effects of N addition on microstructure and mechanical properties of $\mathrm{CoCr}$ FeNiMn high entropy alloy produced by mechanical alloying and vacuum hot pressing sintering. Intermetallics 93:228-234

12. Luo H, Zou S, Chen Y-H, Li Z, Du C, Li X (2020) Influence of carbon on the corrosion behaviour of interstitial equiatomic $\mathrm{CoCr}$ FeMnNi high-entropy alloys in a chlorinated concrete solution. Corr Sci 163:108287

13. Ludwigson DC (1971) Modified stress-strain relation for fcc metals and alloys. Metall Trans - Phys Metall Mater Sci 2:2825-2828

14. Kaspar R, Faul H (2001) Charpy-V subsize specimens - measurements of steel impact properties. Materialprufung 43(1-2):18-21

15. Kleff J (1994) Warmritzen metallischer Werkstoffe. Ph.D. Thesis, Ruhr-Universität Bochum. VDI Reihe 5 Nr. 340:Düsseldorf: VDI-Verlag

16. Kim JH, Lim KR, Won JW, Na YS, Kim H-S (2018) Mechanical properties and deformation twinning behavior of as-cast $\mathrm{CoCr}$ FeMnNi high-entropy alloy at low and high temperatures. Mater Sci Eng A 712:108-113

17. Otto F, Dlouhy A, Somsen Ch, Bei H, Eggeler G, George EP (2013) The influences of temperature and microstructure on the tensile properties of a CoCrFeMnNi high-entropy alloy. Acta Materialia 61:5743-5755

18. Wu Z, Parish CM, Bei H (2015) Nano-twin mediated plasticity in carbon-containing FeNiCoCrMn high entropy alloys. J Alloys Compd 647:815-822

19. Astafurova EG, Reunova KA, Melnikov EV, Panchenko MYu, Astafurov SV, Maier GG, Moskvina VA (2020) On the difference in carbon- and nitrogen-alloying of equiatomic FeMnCrNiCo highentropy alloy. Mater Lett 276:128183

20. Xiong F, Fu R, Li Y, Xu B, Qi X (2021) Influences of nitrogen alloying on microstructural evolution and tensile properties of $\mathrm{CoCr}$ FeMnNi high-entropy alloy treated by cold-rolling and subsequent annealing. Mater Sci Eng A 787:139472

21. Traversier $M$, Mestre-Rinn P, Peillon N, Rigal E, Boulnat $X$, Tancret F, Dhers J, Fraczkiewicz A (2021) Nitrogen-induced hardening in an austenitic $\mathrm{CrFeMnNi}$ high-entropy alloy (HEA). Mater Sci Eng A 804:140725

22. Zhang W, Yan D, Lu W, Li Z (2020) Carbon and nitrogen co-doping enhances phase stability and mechanical properties of a metastable high-entropy alloy. J Alloys Compd 831:154799 
23. Gavriljuk VG, Tyshchenko Al, Bliznuk VV, Yakovleva IL, Riedner S, Berns $\mathrm{H}$ (2008) Cold work hardening of high-strength austenitic steels. Steel Res Int 79:413-422

24. Gavriljuk VG, Berns H (1999) High nitrogen steels: structure, properties, manufacture, applications. Springer-Verlag, Berlin

25. Czichos H, Habig K (2010) Tribologie-Handbuch, Vieweg + Teubner, Wiesbaden, 3. Auflage

26. Xiao J-K, Tan H, Chen J, Martini A, Zhang C (2020) Effect of carbon content on microstructure, hardness and wear resistance of CoCrFeMnNiCx high-entropy alloys. J Alloys Compd 847:156533. https://doi.org/10.1016/j.allcom.2020.156533

27. Jargelius-Petterson R (1998) The influence of N, Mo and Mn on the microstructure and corrosion resistance of austenitic stainless steels, Dissertation. Tekniska högsk, Stockholm

28. Szklarska-Smialowska Z (1986) Pitting corrosion of metals. NACE International, Houston

29. Niederhofer P, Huth $S$ (2013) Cavitation erosion resistance of high interstitial $\mathrm{CrMnCN}$ austenitic stainless steels. Wear 301:457-466

30. Pinto $H$ (2005) Effect of Temperature and Environment on the Deformation Mechanisms of Austenitic Steels during Cryogenic Wear. Technische Universität Berlin (Ph.D. Thesis)
31. Riedner S (2010) Höchstfeste nichtrostende austenitische CrMnstähle mit $(\mathrm{C}+\mathrm{N})$. PhD Thesis, Ruhr-Universität Bochum

32. Lu C-W, Lu Y-S, Lai Z-H, Yen H-W, Lee Y-L (2020) Comparative corrosion behavior of Fe50Mn30Co10Cr10 dual-phase highentropy alloy and CoCrFeMnNi high-entropy alloy in $3.5 \mathrm{wt} \%$ $\mathrm{NaCl}$ solution. J Alloys Compd. https://doi.org/10.1016/j.jallcom. 2020.155824

33. J. Menghani, A. Vyas A, Patel P, Natu H, More S (2020) Wear, erosion and corrosion behavior of laser cladded high entropy alloy coatings - A review, Materials Today: Proceedings, in press, https://doi.org/10.1016/j.matpr.2020.08.763

34. Herbsleb G (1981) Der Einfluss von Legierungselementen auf das Passivierungsverhalten nichtrostender Stähle. VDIZeitschrift 123(12):505-511

35. Zeng $Q, X u Y$ (2020) A comparative study on the tribocorrosion behaviors of AIFeCrNiMo high entropy alloy coatings and 304 stainless steel. Mater Today Commun. https://doi.org/10.1016/j. mtcomm.2020.101261

Publisher's Note Springer Nature remains neutral with regard to jurisdictional claims in published maps and institutional affiliations. 